University of Nebraska - Lincoln

DigitalCommons@University of Nebraska - Lincoln

Faculty Papers and Publications in Animal

Science

Animal Science Department

October 1988

\title{
COMPARISON OF METHODS OF PREDICTING BREEDING VALUES OF SWINE
}

J. W. Keele

R. K. Johnson

University of Nebraska-Lincoln, rjohnson5@unl.edu

L. D. Young

T. E. Socha

Follow this and additional works at: https://digitalcommons.unl.edu/animalscifacpub

Part of the Animal Sciences Commons

Keele, J. W.; Johnson, R. K.; Young, L. D.; and Socha, T. E., "COMPARISON OF METHODS OF PREDICTING BREEDING VALUES OF SWINE" (1988). Faculty Papers and Publications in Animal Science. 45.

https://digitalcommons.unl.edu/animalscifacpub/45

This Article is brought to you for free and open access by the Animal Science Department at DigitalCommons@University of Nebraska - Lincoln. It has been accepted for inclusion in Faculty Papers and Publications in Animal Science by an authorized administrator of DigitalCommons@University of Nebraska Lincoln. 


\title{
COMPARISON OF METHODS OF PREDICTING BREEDING VALUES OF SWINE ${ }^{1,2}$
}

\author{
J. W. Keele ${ }^{3}$, R. K. Johnson ${ }^{4}$, L. D. Young ${ }^{3}$ and T. E. Socha ${ }^{5}$ \\ U.S. Department of Agriculture, Clay Center, NE 68933 and \\ University of Nebraska, Lincoln 68583-0908
}

\begin{abstract}
Best linear unbiased predictions (BLUP) using information from all known relatives; selection index using phenotype, full-sib average and half-sib average; and phenotypic deviation from contemporary group average were compared as methods of predicting breeding values for days to $100 \mathrm{~kg}$ and backfat. Swine records $(\mathrm{n}=203,869)$ from five Hampshire, one Duroc and six Yorkshire herds were obtained from the Nebraska SPF Swine Accrediting Agency. Heritability values used to compute BLUP or index were either estimates based on within-breed offspring on parent regression or values recommended by the National Swine Improvement Federation (NSIF) guidelines. Within-breed estimates of heritability ranged from .11 to .25 for days to $100 \mathrm{~kg}$ and from .10 to .22 for backfat. Heritabilities recommended by NSIF were .35 for days to $100 \mathrm{~kg}$ and .40 for backfat. Correlations between index and phenotypic deviation were larger than correlations between BLUP and phenotypic deviation or BLUP and index. Correlations between BLUP and index were slightly larger than correlations between BLUP and phenotypic deviation. Increasing the heritability values used to compute BLUP or index increased the correlations among methods. Value of heritability had little effect on the correlation between a parent's predicted breeding value and its progeny average. On the average and assuming the NSIF heritability, the correlation between BLUP of a sire and its progeny average was $33 \%$ larger for days to $100 \mathrm{~kg}$ and $44 \%$ larger for backfat than the correlation between the phenotypic deviation of a sire and its progeny average. The advantage of BLUP over phenotypic deviation for dams was less than for sires: $25 \%$ for days to $100 \mathrm{~kg}$ and $18 \%$ for backfat. Selection of pigs using BLUP instead of phenotypic deviation or index would substantially improve response to selection.

(Key Words: Backfat, Growth Rate, Breeding Value, Pigs, Prediction, Selection.)
\end{abstract}

\section{Introduction}

Response to selection (R) is proportional to the correlation ( $\mathrm{r}$ ) between the criterion upon which selection is based and the pig's breeding

\footnotetext{
${ }^{1}$ Published as Paper No. 8592, Journal Series, Nebraska Agric. Res. Div., Lincoln.

${ }^{2}$ This paper was prepared while the senior author was a post-doctoral research associate in the Anim. Sci. Dept. at the Univ. of Nebraska, Lincoln.

${ }^{3}$ Roman L. Hruska U.S. Meat Anim. Res. Center, ARS, USDA, Clay Center, NE.

${ }^{4}$ Anim. Sci. Dept., Univ. of Nebraska, Lincoln.

${ }^{5}$ Nebraska SPF Swine Accrediting Agency, Vet. Basic Sci., Univ. of Nebraska, Lincoln.

Received March 30, 1988.

Accepted June 12, 1988.
}

value $(R=\operatorname{rih} \sigma)$, where $i$ is the intensity of selection, $h$ is the square root of heritability $\left(\mathrm{h}^{2}\right)$ and $\sigma$ is the phenotypic $\mathrm{SD}$. The phenotype is a good predictor of breeding value for selection among pigs within a contemporary group if $h^{2}$ is high. When $h^{2}$ is moderate to low, predictors such as selection index and BLUP that incorporate information from relatives can significantly improve response to selection over selection on phenotype (Lush, 1947).

Best linear unbiased predictions have the highest correlations with the pig's true breeding values compared to all other predictors if 1$) \mathrm{h}^{2}$ and $c^{2}$ (the proportion of the variation due to environmental effects common to the litter) are known, 2) the data are distributed normally, 3) all relationships among animals are known, 4) 
previous selection was imposed using a predictor that was adjusted in an unbiased manner for effects of contemporary groups and 5) the data upon which selection was based are included in the analysis (Henderson, 1975). At least one of these assumptions may not be true; for example, $h^{2}$ and $\mathrm{c}^{2}$ may not be known.

The purpose of this study was to compare 1) best linear unbiased prediction using information from all known relatives; 2) selection index using phenotype, average of full-sibs and average of half-sibs; and 3) phenotypic deviation from contemporary group average as measures to rank pigs for selection using growth and backfat data from Nebraska seedstock herds. A second objective was to estimate heritability for days to $100 \mathrm{~kg}$ and backfat probe.

\section{Data and Methods}

Data. Birth records of 203,869 purebred pigs from five Hampshire, one Duroc and six Yorkshire herds were obtained from the Nebraska SPF Swine Accrediting Agency. Pigs were born between 1960 and 1986 . Numbers of records per herd ranged from 8,687 to 16,268 for Yorkshire and from 3,417 to 10,279 for Hampshire. Number of records per breed were 28,681 for Hampshire, 100,455 for Duroc and 74,733 for Yorkshire. The traits considered were days to $100 \mathrm{~kg}$ and average backfat probe at $100 \mathrm{~kg}$. Data and adjustment of data for pigs not weighing $100 \mathrm{~kg}$ when weighed were described in detail by David et al. (1983). Analyses were done separately for each traitbreed combination.

Model. The model assumed for BLUP included the average effects of genes for animals (animal effects), effects of farm $x$ year $x$ farrowing group $x$ sex subclasses (contemporary groups), environmental effects common to littermates (litter effects) and effects of genetic groups common to pigs with unknown parents born on the same farm in the same year. Contemporary groups were cross-classified with litters because males and females of the same litter were in different contemporary groups. The variance-covariance matrix among effects due to animal, litter and environment is

$$
\sigma^{2} \quad\left[\begin{array}{rrr}
h^{2} A & 0 & 0 \\
0 & c^{2} I & 0 \\
0 & 0 & \left(1-h^{2}-c^{2}\right) I
\end{array}\right]
$$

where $\mathbf{A}$ is Wright's numerator relationship matrix and I represents an identity matrix of appropriate size. Therefore, the variance among the phenotypes is $\sigma^{2}\left[h^{2} \mathbf{Z} A Z^{\prime}+c^{2} L L^{\prime}+\right.$ $\left.\left(1-h^{2}-c^{2}\right) \mathbf{I}\right]$, where $Z$ and $L$ are incidence matrices relating animals and litters to phenotypes. All known relationships among animals were accounted for by using Henderson's rules for computing the elements of $\mathrm{A}^{-1}$ (Henderson, 1976). Inbreeding was not considered in computation of $\mathrm{A}^{-1}$. Contemporary group and genetic group were regarded as fixed. The genetic group for a pig that had known parents was the average genetic group of its parents. Genetic groups were accounted for with BLUP using a procedure described by Westell et al. (1988).

Edits. The editing performed prior to computing BLUP is shown in Table 1. Partial duplicates of records arose when pigs were weighed and(or) probed more than once. When this occurred, a single record was randomly selected from the duplicate identifications. Information on the parentage of sire and dam of a pig was available only if they had a record of performance as a young animal. A sire or dam that did not have a record had unknown parents. However, the parents of some sires and dams without records as young animals could be determined by a cross-reference with the records of full-sibs. Based on the SPF identification, full-siblings could be identified even when their parents were unknown. Therefore, pseudo parents were generated to allow BLUP to account for these full-sib relationships.

Calculation of Predicted Breeding Values. The BLUP evaluations were computed by iterating on the data using a procedure similar to that described by Schaeffer and Kennedy (1986) with modifications made to account for genetic groups of pigs with unknown parents and cross-classification of contemporary group with litter. The BLUP evaluations for parents were computed using records of animals born before the birth-year of the progeny that they were identified with. For example, for progeny born in 1980, records of siblings, ancestors and progeny born prior to 1980 were used to compute BLUP for parents, but not the progeny born in 1980 or after. This does not influence index or phenotypic deviations because only contemporary records were used in obtaining these quantities.

A sib-index based on the phenotype of the individuals and the average performance of full- 


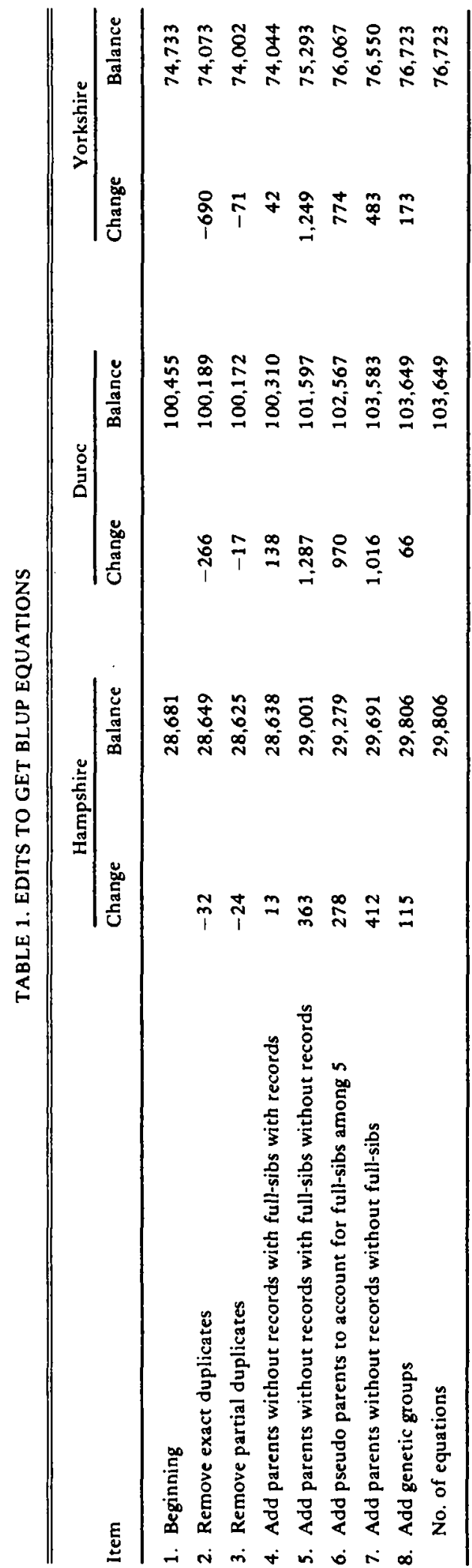

and half-sibs was computed (Van Vleck, 1983). Some of the pigs did not have full-sibs, some did not have half-sibs and some had neither fullnor half-sibs. Rather than eliminating pigs with incomplete data from the analyses, indices were computed for the specific information that was available for the pig. The percentages of indices with different amounts of sib-information are given in Table 2. Most of the pigs had both full-sibs and half-sibs.

The phenotype used for the prediction of breeding value and used in computing the sib-index was expressed as a deviation from contemporary group average. The contemporary group was defined as the farm $x$ year $x$ farrowing group $x$ sex subclass.

Heritability Values Used. To evaluate the sensitivity of the results to the value of $h^{2}$ used, BLUP and index were computed with two different values for $h^{2}$. One set of values was estimated from the data by regression of offspring on parent, and the other set was .35 for days to $100 \mathrm{~kg}$ and .40 for backfat. The National Swine Improvement Federation (NSIF) guidelines (1987) recommend .35 for days to $104.4 \mathrm{~kg}$ and .40 for backfat. A value of .05 was chosen for $\mathrm{c}^{2}$ after reviewing the literature (e.g., Hutchens and Hintz, 1981). The value for $\mathrm{c}^{2}$ was held constant at .05 for all analyses.

Heritability Estimation. Heritability was estimated by multiple regression of offspring phenotype on the phenotypic deviation of the sire and dam from their respective contemporary group averages. Multiple regression was used to account for assortative mating if it occurred. Phenotypic deviations of sires and dams were repeated for every progeny. Effects of contemporary group of the progeny were absorbed into the equations for sires and dams. The heritability estimate was obtained by taking the sum of the regression coefficients for the sire and dam. Estimates of $h^{2}$ were obtained for each breed separately, and an overall estimate pooled across breeds was computed. The within-breed estimates were used to compute BLUP and index.

Criterion for Comparison of Methods. Methods of predicting breeding value were compared based on the correlation between the predicted breeding value of a parent and the average phenotype of its progeny within contemporary group of progeny. Agreement between methods was assessed using productmoment correlations among predicted breeding values of parents estimated by the three proce- 
TABLE 2. PERCENTAGE OF OBSERVATIONS IN DIFFERENT INDEX CATEGORIES

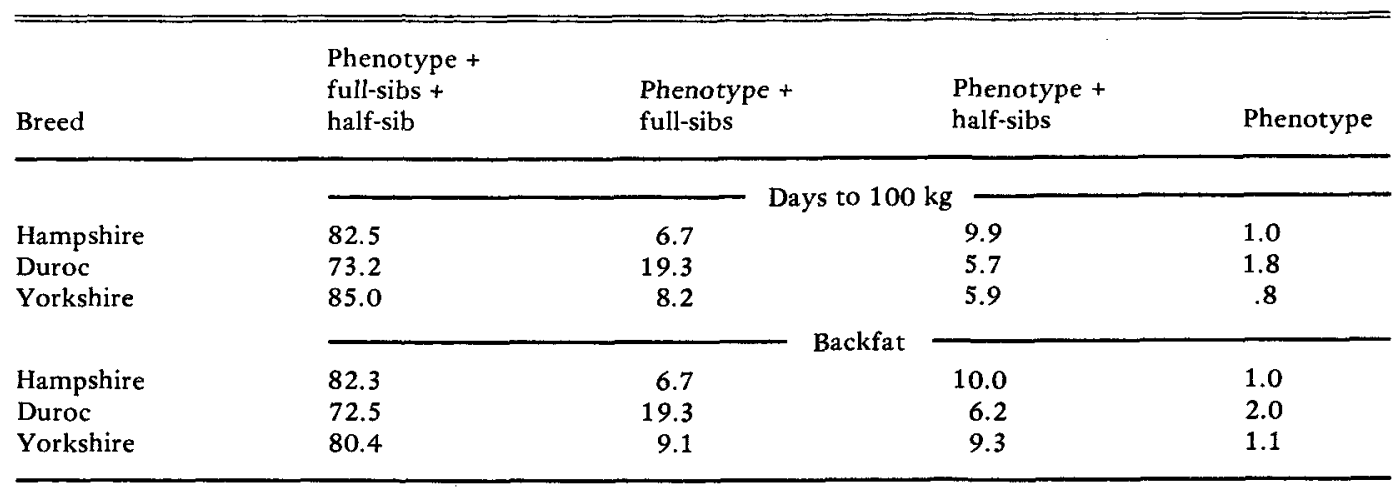

dures calculated within contemporary group of progeny. These correlations are biased by selection. The correlation of a parent's phenotype and its progeny average is biased downward more by selection than the correlation of a parent's BLUP or index and its progeny average. Therefore, to be fair to the phenotype method of breeding value estimation, these correlations should be adjusted for selection on the phenotype (Table 3). On the other hand, it is doubtful that phenotypic truncation selection was the only form of selection practiced. If the selection practiced was not strict phenotypic truncation selection, then upward adjustment of the correlations for bias due to phenotypic truncation selection would be too large for the correlation of a parent's phenotype and its progeny average and too small for the correlation of a parent's BLUP or index and its progeny average. In other words, if we adjust the correlations for phenotypic truncation selection and the assumption of truncation selection is in error, the error will be in favor of phenotypic deviation and against index or BLUP. The adjusted correlations are conservative in the

TABLE 3. ESTIMATED PHENOTYPIC VARIANCE OF PARENTS DIVIDED BY PHENOTYPIC VARIANCE AMONG ALL PIGS

\begin{tabular}{|c|c|c|c|c|}
\hline \multirow[b]{2}{*}{ Breed } & \multicolumn{2}{|c|}{ Days to $100 \mathrm{~kg}$} & \multicolumn{2}{|c|}{ Backfat } \\
\hline & Sires & Dams & Sires & Dams \\
\hline Hampshire & .28 & .34 & .75 & 1.09 \\
\hline Duroc & .44 & .41 & .60 & .84 \\
\hline Yorkshire & .17 & .38 & .53 & 1.11 \\
\hline Pooled & .35 & .39 & .63 & .95 \\
\hline
\end{tabular}

sense that the phenotypic deviation method is given the benefit of the doubt.

The correlations among the progeny averages and the predicted breeding values of parents were adjusted for selection following Robertson (1977). The ratio of phenotypic variance after selection to phenotypic variance before selection is needed to make these adjustments. We used the variance of phenotypic deviations from contemporary group means of parents (within contemporary group of progeny mean square) divided by phenotypic variance (within contemporary group of pig mean square) of all pigs. These values are given in Table 3 .

\section{Results and Discussion}

Limitations of the Data. The number of parents was 6,004 for Durocs, 1,781 for Hampshire and 3,979 for Yorkshire. Because sire and dam are identified on the birth record, parents without birth records result in missing relationships. If some parents are missing birth records, genetic ties and cross-links are not available to BLUP that potentially would be available in a seedstock population with more complete records. Because phenotype and index don't use these relationships, a comparison of these methods with BLUP using data sets that include parents with missing birth records is somewhat unfair to BLUP. The percentage of parents without birth-records was 38.4 for Durocs and $\mathbf{4 3 . 5}$ for Hampshires and Yorkshires. Of the parents without birth-records, $60.3 \%$ were littermates with at least one other parent that also did not have a birth-record. This full-sib relationship was accounted for with BLUP by generating a pseudo parent. However, half-sib relationships among pigs without 
birth-records could not be determined and were not accounted for. There are three possible explanations for pigs without birth records: 1) the pig is a true emigrant or a base generation animal, 2) Nebraska SPF has no record of the parents of pigs that were brought into the herd through primary SPF procedures (denoted lab-pigs) or 3) the record of the pig was lost from the files when data were moved from cards to tape. The third explanation is possible because some of the cards were difficult or impossible to read because they were warped after several years of storage. In most cases, lab-pigs were true emigrants; however, in a few cases the dam of a lab-litter might be from the population. The loss of pedigree information could result in two nonzero covariances between phenotypes to be incorrectly set to zero when computing BLUP. These are 1) covariances among phenotypes of half-first cousins, which are equal to $h^{2} \sigma^{2} / 16$, and 2) covariances between the phenotypes of pigs and their grandparents, which are equal to $h^{2} \sigma^{2} / 4$. It is doubtful that the first error would have any measurable effect on the precision or accuracy of BLUP. However, the second error could greatly reduce the effectiveness of BLUP in adjusting for bias due to selection, because the genetic ties between generations would not be accounted for, and the phenotypes upon which selection was based (phenotypes of parents without records) would not be included in the analysis. Loss of pedigree information would have no effect on the accuracy or precision of phenotypic deviation or index.

Heritability Estimates. A relatively small portion of the records could be used to estimate $\mathrm{h}^{2}$ because phenotypes on both the sire and dam were needed. The percentage of records that had days to $100 \mathrm{~kg}$ for the pig, sire and dam was $\mathbf{3 0 . 6}$ for Durocs, $\mathbf{1 7 . 1}$ for Hampshire and 13.4 for Yorkshire. The percentage of records that had backfat for the pig, sire and dam was 20.6 for Durocs, 10.9 for Hampshire and 7.6 for Yorkshire. The estimates of heritability by regression of offspring on parent are given in Table 4 . Over $60 \%$ of the data were from the Duroc herd, so the pooled estimates were very similar to the estimates from the Duroc herd.

Estimates of heritability in the literature vary widely (Hutchens and Hintz, 1981; David et al., 1983; Kennedy et al., 1985; Bereskin, 1987). In spite of this, the general conclusion of swine geneticists is that $h^{2}$ is near .35 for days to $104.4 \mathrm{~kg}$ and .40 for backfat as indicated by the National Swine Improvement Federation (NSIF) guidelines (1987). The estimates of $h^{2}$ from the current study (Table 4) all were less than the values recommended by NSIF. This discrepancy between the estimates from the current study and the values recommended by NSIF could be due to bias caused by selection of progeny to be tested. Of the 202,799 birth-records analyzed, $72 \%$ had information on days to $100 \mathrm{~kg}$ and $45 \%$ had information on backfat. Causes for missing phenotypes were not known, but mortality before weaning could account for most of the pigs that were missing records for days to $100 \mathrm{~kg}$ (Fahmy and Bernard, 1971). Large piglets grow faster and are less likely to die than small piglets. Pigs that had backfat data were selected based on their growth rate (David et al., 1983). Growth rate

TABLE 4. OFFSPRING ON PARENT REGRESSIONS AND RESULTING ESTIMATES OF HERITABILITY

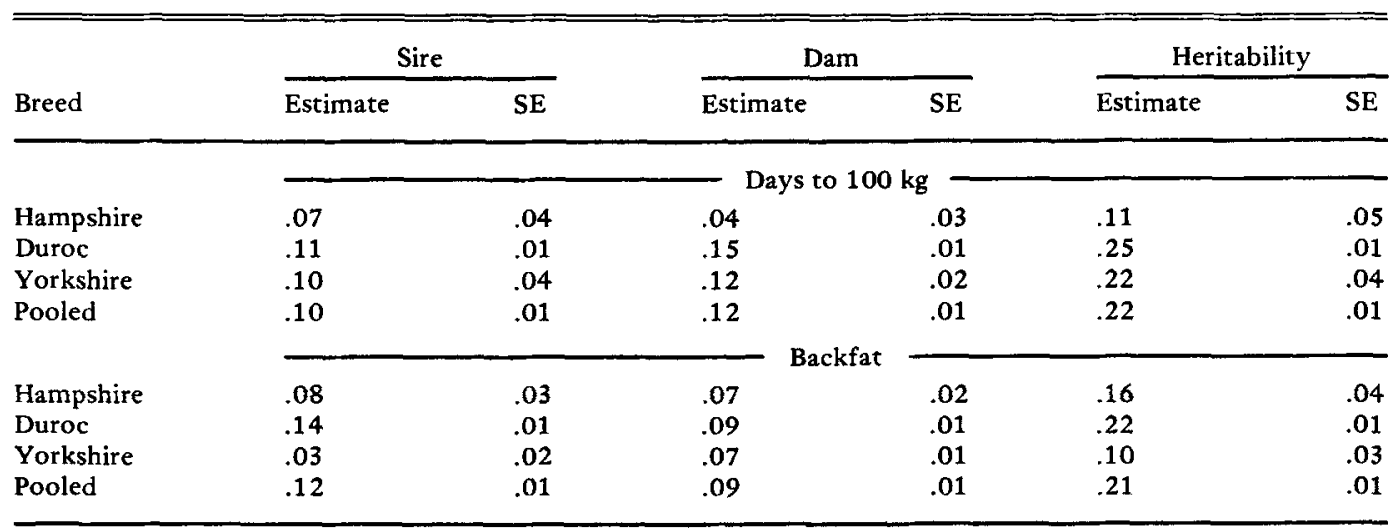


has a small positive phenotypic correlation with backfat (Bereskin, 1987). Therefore, the criterion used to select the pigs that would have phenotypes probably had a positive correlation with the phenotypes.

To obtain an upper bound on the possible bias due to selection, suppose that the criterion for selection of pigs that would have phenotypes had a correlation of 1 with the phenotype. The proportional decrease in the expected value of the estimates of $h^{2}$ due to truncation selection is $h^{2} i(i-x)$, where $i$ is the intensity of selection and $\mathrm{x}$ is the deviation of the point of truncation from the population mean in SD units (Robertson, 1977). This assumes that the variance among parents is not affected by selection. This is a conservative assumption in that the selection bias on the estimates of $h^{2}$ is greater under this assumption than it would be under the assumption that the phenotypic variance among parents was reduced by selection. Assuming the heritability values from the NSIF guidelines, the most that the heritability estimates by regression of offspring on parent could be biased downward is $17 \%$ for days to $100 \mathrm{~kg}$ and $26 \%$ for backfat. Reducing the
NSIF heritabilities by these percentages yields .29 for days to $100 \mathrm{~kg}$ and .30 for backfat, values that still are larger than the estimates from the current study. Therefore, the discrepancy between estimates of heritability from the current study and the values recommended by NSIF cannot be explained solely by bias due to selection of progeny. David et al. (1983) suggested that the low estimates of heritability that they obtained from some of the same data compared to results from experiments might be due to more heterogeneous environments for SPF pigs compared to pigs from experiments. Another explanation is that contemporary groups probably are less correctly specified in private seedstock herds than in experimental herds. Incorrect specification of contemporary groups could inflate the environmental variance and thus reduce heritability. Also, pigs from seedstock herds might be more genetically uniform than pigs from experiment stations.

Correlations Among Methods. Correlations among methods of predicting breeding values of sires or dams adjusted for truncation selection on the phenotype are given in Table 5. Correlations in Table 5 can be considered upper

TABLE 5. PRODUCT-MOMENT CORRELATIONS AMONG METHODS OF PREDICTING BREEDING VALUES OF PARENTS ADJUSTED FOR SELECTION ON PHENOTYPE

\begin{tabular}{|c|c|c|c|c|c|c|}
\hline \multirow[b]{2}{*}{ Breed } & \multicolumn{3}{|c|}{ Estimated heritability } & \multicolumn{3}{|c|}{ NSIFa heritability } \\
\hline & $\begin{array}{l}\text { Phenotype- } \\
\text { index }\end{array}$ & $\begin{array}{l}\text { Phenotype- } \\
\text { BLUP }\end{array}$ & $\begin{array}{l}\text { Index- } \\
\text { BLUP }\end{array}$ & $\begin{array}{l}\text { Phenotype- } \\
\text { index }\end{array}$ & $\begin{array}{l}\text { Phenotype- } \\
\text { BLUP }\end{array}$ & $\begin{array}{l}\text { Index- } \\
\text { BLUP }\end{array}$ \\
\hline & \multicolumn{6}{|c|}{ Sires (days to $100 \mathrm{~kg}$ ) } \\
\hline Hampshire & .91 & .39 & .56 & .97 & .67 & .74 \\
\hline Duroc & .94 & .62 & .65 & .96 & .67 & .69 \\
\hline Yorkshire & .96 & .69 & .71 & .98 & .78 & .79 \\
\hline \multirow[t]{2}{*}{ Pooled } & .95 & .64 & .67 & .96 & .70 & .72 \\
\hline & \multicolumn{6}{|c|}{ Dams (days to $100 \mathrm{~kg}$ ) } \\
\hline Hampshire & .84 & .53 & .66 & .94 & .76 & .79 \\
\hline Duroc & .90 & .76 & .81 & .93 & .81 & .84 \\
\hline Yorkshire & .89 & .63 & .69 & .93 & .73 & .76 \\
\hline \multirow[t]{2}{*}{ Pooled } & .88 & .69 & .76 & .93 & .78 & .81 \\
\hline & \multicolumn{6}{|c|}{ - Sires (backfar) } \\
\hline Hampshire & .87 & .58 & .72 & .95 & .72 & .80 \\
\hline Duroc & .91 & .61 & .70 & .95 & .72 & .78 \\
\hline Yorkshire & .82 & .62 & .58 & .93 & .81 & .77 \\
\hline \multirow[t]{2}{*}{ Pooled } & .89 & .60 & .68 & .95 & .72 & .76 \\
\hline & \multicolumn{6}{|c|}{ - Dams (backfat) } \\
\hline Hampshire & .84 & .64 & .69 & .93 & .78 & .80 \\
\hline Duroc & .85 & .67 & .75 & .92 & .80 & .84 \\
\hline Yorkshire & .77 & .55 & .63 & .92 & .75 & .77 \\
\hline Pooled & .79 & .62 & .72 & .92 & .78 & .81 \\
\hline
\end{tabular}

\footnotetext{
${ }^{a}$ NSIF $=$ National Swine Improvement Federation
} 
bounds because we are not sure that truncation selection occurred. In the face of uncertainty about whether or not truncation selection on the phenotype occurred, we are assuming that it is more conservative to make the error of concluding that the methods agree when in fact they disagree than it is to make the error of concluding that they disagree when in fact they agree. Correlations between phenotypic deviation and index indicate agreement between these methods. On the other hand, BLUP was quite different from index and phenotypic deviation, and it was slightly more similar to index than to phenotypic deviation. Increasing the value of $h^{2}$ to the NSIF value instead of to the estimated value for index and BLUP made the methods more similar.

Mabry et al. (1987) reported results from central test station data that are in agreement with the current study in that rank correlations between phenotypic deviations from contemporary group mean and BLUP were significantly less than 1 (.78 for ADG and .84 for backfat) but were larger in magnitude than the productmoment correlations from the current study.

Correlations with Progeny Average. The correlations between progeny average and predicted breeding value of parent adjusted for truncation selection on the phenotype are given in Table 6. The difference between the correlation of BLUP or index of a sire or dam with its progeny average and the correlation of phenotypic deviation of a sire or dam with its progeny average probably is lower than the true difference between these correlations because we are not sure that truncation selection occurred. In the face of uncertainty about whether or not truncation selection on the phenotype occurred, we are assuming that it is more conservative to make the error of concluding that BLUP or index is the same as or worse than phenotype when in fact it is better than it is to make the error of concluding that BLUP or index is better than phenotype when in fact it is not. This assumption is justified by the fact that the status quo in the U.S. swine seedstock industry is no selection (David et al., 1983) or selection on phenotype or indices that utilize information from other traits but not information from relatives.

In light of the high correlation between phenotypic deviation and index, it was no surprise that the correlation between progeny average and predicted breeding value of parent

TABLE 6. PRODUCT-MOMENT CORRELATIONS OF AVERAGE PHENOTYPE OF PROGENY WITH PREDICTED BREEDING VALUE OF SIRE OR DAM ADJUSTED FOR SELECTION ON PHENOTYPE

\begin{tabular}{|c|c|c|c|c|c|c|}
\hline \multirow[b]{2}{*}{ Breed } & \multicolumn{3}{|c|}{ Estimated heritability } & \multicolumn{3}{|c|}{ NSIF ${ }^{a}$ heritability } \\
\hline & Phenotype & Index & BLUP & Phenotype & Index & BLUP \\
\hline & \multicolumn{6}{|c|}{ Sires (days to $100 \mathrm{~kg}$ ) } \\
\hline Hampshire & .22 & .24 & .32 & .22 & .23 & .31 \\
\hline Duroc & .14 & .14 & .20 & .14 & .14 & .19 \\
\hline Yorkshire & .09 & .09 & .16 & .09 & .09 & .15 \\
\hline Pooled & .15 & .15 & .21 & .15 & .15 & .20 \\
\hline & \multicolumn{6}{|c|}{ - Dams (days to $100 \mathrm{~kg}$ ) } \\
\hline Hampshire & .07 & .09 & .10 & .07 & .08 & .10 \\
\hline Duroc & .16 & .15 & .19 & .16 & .15 & .19 \\
\hline Yorkshire & .09 & .08 & .12 & .09 & .09 & .12 \\
\hline \multirow[t]{2}{*}{ Pooled } & .12 & .12 & .15 & .12 & .12 & .15 \\
\hline & \multicolumn{6}{|c|}{ - Sires (backfat) } \\
\hline Hampshire & .22 & .23 & .25 & .22 & .23 & .25 \\
\hline Duroc & .17 & .19 & .25 & .17 & .19 & .25 \\
\hline Yorkshire & .10 & .07 & .13 & .10 & .08 & .10 \\
\hline \multirow[t]{2}{*}{ Pooled } & .16 & .18 & .24 & .16 & .18 & .23 \\
\hline & \multicolumn{6}{|c|}{ - Dams (backfat) - } \\
\hline Hampshire & .10 & .10 & .13 & .10 & .10 & .12 \\
\hline Duroc & .12 & .12 & .16 & .12 & .12 & .16 \\
\hline Yorkshire & .11 & .08 & .11 & .10 & .09 & .10 \\
\hline Pooled & .11 & .10 & .14 & .11 & .11 & .13 \\
\hline
\end{tabular}

\footnotetext{
${ }^{\mathbf{a}}$ NSIF $=$ National Swine Improvement Federation.
} 
TABLE 7. AVERAGE AND MAXIMUM EXPECTED CORRELATION OF PHENOTYPE OR INDEX WITH THE TRUE BREEDING VALUE FOR ESTIMATED OR NATIONAL SWINE IMPROVEMENT FEDERATION (NSIF) HERITABILITY

\begin{tabular}{|c|c|c|c|c|c|c|}
\hline \multirow[b]{3}{*}{ Breed } & \multicolumn{3}{|c|}{ Estimated heritability } & \multicolumn{3}{|c|}{ NSIF heritability } \\
\hline & \multirow[b]{2}{*}{ Phenotype } & \multicolumn{2}{|c|}{ Index } & \multirow[b]{2}{*}{ Phenotype } & \multicolumn{2}{|c|}{ Index } \\
\hline & & Mean & Max. & & Mean & $\operatorname{Max}$ \\
\hline & & & - Da & kg - & & \\
\hline Hampshire & .33 & .44 & .53 & .59 & .66 & .70 \\
\hline Duroc & .50 & .57 & .63 & .59 & .65 & .69 \\
\hline Yorkshire & .47 & .56 & .63 & .59 & .66 & .70 \\
\hline Hampshire & .40 & .49 & .57 & .63 & .69 & .72 \\
\hline Duroc & .47 & .54 & .61 & .63 & .68 & .72 \\
\hline Yorkshire & .32 & .41 & .51 & .63 & .69 & .72 \\
\hline
\end{tabular}

did not differ whether the predicted breeding value was index or phenotype. The small average number of pigs per full-sib family (average numbers for all three breeds was close to 3 ) and half-sib family (average numbers for the three breeds ranged from 6 to 11) indicate that there was little information to be gained from utilizing phenotypes from siblings. The small average number of pigs per contemporary group (average numbers for the three breeds ranged from 32 to 64 ) suggests that the index was not adjusted accurately for contemporary group average. Selection index theory assumes that the contemporary group averages are known without error. The average expected correlation (Table 7) between a pig's index and its breeding value for the three breeds was 8 to $33 \%$ larger than the expected correlation (h) between a pig's phenotypic deviation and its breeding value. The largest expected correlation of a pig's index and its breeding value for the three breeds was 14 to $61 \%$ larger than h. The observed correlations (Table 6) do not show as much advantage for index over phenotypic deviation as expected based on quantitative genetics theory for random mating populations. The lack of advantage of index over phenotypic deviation could be due to selection, small contemporary groups or chance fluctuations.

The correlation of progeny average with predicted breeding value of parent was similar for $h^{2}$ estimated from the data or the NSIF $h^{2}$ (Table 6). This observation is in agreement with the conclusion of Sales and Hill (1976) that errors in $\mathrm{h}^{2}$ have small effects on the accuracy of selection indexes that utilize information from relatives.

Pooled across breed and assuming the NSIF heritability, the correlation of progeny average with BLUP of sire was $33 \%$ higher for days to $100 \mathrm{~kg}$ and $44 \%$ higher for backfat than the correlation of progeny average with phenotypic deviation of sire. The advantage of BLUP over phenotypic deviation was less for dams than for sires. Pooled across breed and assuming NSIF $h^{2}$, the correlation of progeny average with BLUP of dam was $25 \%$ higher for days to 100 $\mathrm{kg}$ and $18 \%$ higher for backfat than the correlation of progeny average with phenotypic deviation of dam. Within-breed correlations of progeny average with BLUP of parent were larger than correlations of progeny average with phenotypic deviation or index of parent in all cases except for backfat for Yorkshire, where BLUP and phenotypic deviation were equal. Coincidently, this also was the only case in which there was an effect of heritability value used in computing BLUP or index on the correlation of progeny average with predicted breeding value of parent.

The results of the current study are in agreement qualitatively with a simulation study of Belonsky and Kennedy (1988) that showed a relative advantage of selection on BLUP over selection on phenotype of $55 \%$ for $\mathrm{h}^{2}=.10$, $25 \%$ for $h^{2}=.30$ and $10 \%$ for $h^{2}=.60$ after 10 $\mathrm{yr}$ of selection. There is a misconception among animal breeders that the increased accuracy of BLUP over phenotype or sib-index comes at the expense of increased generation interval. It should be emphasized that the simulation study 
of Belonsky and Kennedy shows an advantage of BLUP without increasing the generation interval. In fact, they demonstrated that selection using BLUP instead of phenotype reduced generation interval.

Differences among methods when young pigs are the only candidates for selection would not be so large as those observed in the current study. Belonsky and Kennedy (1988) observed a greater advantage for selection on BLUP instead of selection on phenotype when all pigs in the herd were candidates for selection instead of a program in which only young pigs were candidates for selection and a fixed proportion of sows and boars were culled every year. One of the major advantages of BLUP over phenotype or index for within-herd selection is in the comparison of young, unproven animals to older, proven animals.

\section{Conclusions}

Response would be greater from selection using BLUP than from selection using sib-index (linear combination of phenotype, full-sib average and half-sib average) or phenotypic deviation. The advantage of BLUP over phenotypic deviation or sib-index would be greater for selection of sires than for selection of dams. There was no evidence that sib-index was more accurate than phenotypic deviation. This is in contrast to expectation based on quantitative genetics theory.

Quantitative genetics theory suggests that the correlation of BLUP of a parent with its progeny average is higher than the correlation of phenotype of a parent with its progeny average if 1) $h^{2}$ and $c^{2}$ are known without error, 2) all relationships between animals are known and 3) the records upon which previous selection was based are included in the analysis. Some causes of pretest selection in the populations of the current study are 1) sale of pigs prior to completion of the test, 2) failure to probe small pigs and 3) castration of small or unsound pigs prior to the test. The records upon which pretest selection was based were not included in the present analyses. These results indicate that 1 ) the differences in accuracy among BLUP, index and phenotype are quite insensitive to the value of $h^{2}$ used in computing BLUP or index and 2) BLUP is more highly correlated with progeny average than sib-index or phenotype, even when we know that some pedigree information was missing and that some pretest selection occurred. In short, we conclude that BLUP is robust to violations in some of the assumptions underlying its theory.

\section{Literature Cited}

Belonsky, G. M. and B. W. Kennedy. 1988. Selection on individual phenotype and best linear unbiased predictor of breeding value in a closed swine herd. J. Anim. Sci. 66:1124.

Bereskin, B. 1987. Genetic and phenotypic parameters for pig growth and body composition estimated by intraclass correlation and parent-offspring regression. J. Anim. Sci. 64:1619.

David, P. J., R. K. Johnson and T. E. Socha. 1983. Genetic and phenotypic parameters estimated from Nebraska specific-pathogen-free swine field records. J. Anim. Sci. 57:1117.

Fahmy, M. H. and C. Bernard. 1971. Causes of mortality in Yorkshire pigs from birth to 20 weeks of age. Can. J. Anim. Sci. 51:351.

Henderson, C. R. 1975. Best linear unbiased estimation and prediction under a selection model. Biometrics 31:423.

Henderson, C. R. 1976. A simple method of computing the inverse of a numerator relationship matrix used in prediction of breeding values. Biometrics 32:69.

Hutchens, L. K. and R. L. Hintz. 1981. A summary of genetic and phenotypic statistics for pubertal and growth characteristics in swine. Oklahoma Agric. Exp. Sta. T-155.

Kennedy, B. W., Kjell Johansson and G.F.S. Hudson. 1985. Heritabilities and genetic correlations for backfat and age at $90 \mathrm{~kg}$ in performance-tested pigs. J. Anim. Sci. 61:78.

Lush, J. L. 1947. Family merit and individual merit as bases for selection. Part I. Am. Nat. 81: 241.

Mabry, J. W., L. L. Benyshek, M. H. Johnson and D. E. Little. 1987. A comparison of methods for ranking boars from different central test stations. J. Anim. Sci. 65:56.

National Swine Improvement Federation. 1987. Guidelines for uniform swine improvement programs (Rev. Ed.). pp 10-12. Program Aid 1157 , USDA, Washington, DC.

Robertson, A. 1977. The effect of selection on the estimation of genetic parameters. Z. Tierz. Zuechtungsbiol. 94:131.

Sales, J. and W. G. Hill. 1976. Effect of sampling errors on efficiency of selection indices. Anim. Prod. 22:1.

Schaeffer, L. R. and B. W. Kennedy. 1986. Computing solutions to mixed model equations. In: Proc. 3rd World Cong. Genet. Appl. to Livest. Prod. XII. p 382.

Van Vleck, D. L. 1983. Notes on the Theory and Application of Selection Principles for the Genetic Improvement of Animals (Rev. Ed.). pp 60-63. Cornell Univ., Ithaca, NY.

Westell, R. A., R. L. Quaas and L. D. Van Vleck. 1988. Genetic groups in an animal model. J. Dairy Sci. $71: 1310$. 